\title{
The CK2 inhibitor CX4945 reverses cisplatin resistance in the A549/DDP human lung adenocarcinoma cell line
}

\author{
CHENGJI JIN ${ }^{1}$, PING SONG ${ }^{1}$ and $\mathrm{JI} \mathrm{PANG}^{2}$ \\ ${ }^{1}$ Respiratory Department, Affiliated Hospital of Jiangsu University, Zhenjiang, Jiangsu 212001; \\ ${ }^{2}$ Department of Physiology, School of Medicine, Jiangsu University, Zhenjiang, Jiangsu 212013, P.R. China
}

Received December 3, 2018; Accepted June 13, 2019

DOI: $10.3892 / \mathrm{ol} .2019 .10696$

\begin{abstract}
Lung cancer negatively impacts global health, and the incidence of non-small cell lung cancer (NSCLC) is highest among all forms of lung cancer. Chemotherapy failure mainly occurs due to drug resistance; however, the associated molecular mechanism remains unclear. Casein kinase II (CK2), which plays important roles in the occurrence, development and metastasis of many tumours, regulates Wnt signaling by modulating $\beta$-catenin expression. In the present study the effects of the CK2 inhibitor, CX4945 on cisplatin [or cis-diamminedichloroplatinum (II); (DDP)]-resistant A549 cells (A549/DDP) were investigated to elucidate the underlying molecular mechanism. A549/DDP cells were divided into four groups (blank control, CX4945, cisplatin and CX4945+cisplatin). Cisplatin resistance was 5.16-fold greater in A549/DDP cells compared with that in A549 cells, with an optimal cisplatin concentration of $5 \mu \mathrm{g} / \mathrm{ml}$. Moreover, levels of CK2, dishevelled-2 (DVL-2) phosphorylated (p) at Ser143 (p-DVL-2 ${ }^{\text {Ser143 }}$, and major Wnt-signaling proteins were significantly higher in A549/DDP cells compared with that in A549 cells $(\mathrm{P}<0.05)$, with these levels further increased following cisplatin treatment $(\mathrm{P}<0.05)$, whereas these levels significantly decreased in A549 cells after cisplatin treatment $(\mathrm{P}<0.05)$. Additionally, multidrug-resistance-associated protein 1 and lung resistance protein expression was significantly higher in A549/DDP cells compared with that in A549 cells $(\mathrm{P}<0.05)$, with these levels increasing further in A549/DDP $(\mathrm{P}<0.05)$
\end{abstract}

Correspondence to: Professor Ping Song, Respiratory Department, Affiliated Hospital of Jiangsu University, 438 Jiefang Road, Zhenjiang, Jiangsu 212001, P.R. China

E-mail: song83938@126.com

Abbreviations: CCK-8, Cell Counting Kit-8; CK2, casein kinase II; DDP, cis-diamminedichloroplatinum (II); DVL-2, dishevelled-2; GSK-3 $\beta$, glycogen synthase kinase- $3 \beta$; $\mathrm{IC}_{50}, 50 \%$ growth inhibition; LRP, lung resistance protein; MRP1, multidrug resistance-associated protein 1; NSCLC, non-small cell lung cancer; RPMI, Roswell Park Memorial Institute; Topo, topoisomerase

Key words: CK2, CX4945, cisplatin resistance, lung cancer, Wnt pathway but not A549 cells upon cisplatin treatment ( $\mathrm{P}>0.05)$. In addition, reduced expression of resistance proteins in A549/DDP cells was accompanied by a decline in the $50 \%$ growth inhibition after CX4945 pre-treatment. Furthermore, levels of p-DVL-2 ${ }^{\text {Ser143 }}$ and major Wnt-signaling proteins decreased significantly after treatment of A549/DDP cells with CX4945+cisplatin, whereas DVL-2 and p-DVL-2 ${ }^{\text {Thr224 }}$ levels remained unchanged. Additionally, significant elevations in apoptosis rates in the CX4945+cisplatin group relative to the control and cisplatin-only groups, was observed $(\mathrm{P}<0.001)$. These results suggested that inhibiting Wnt $/ \beta$-catenin signaling with CX4945, which attenuates levels of drug-resistanceassociated proteins and induces apoptosis, might reverse cisplatin resistance in NSCLC.

\section{Introduction}

Lung cancer is the leading cause of cancer-related mortality worldwide, resulting in $\sim 1.8$ million new cases and $\sim 1.6$ million deaths annually, with non-small cell lung cancer (NSCLC) accounting for $\sim 80 \%$ of all lung cancers (1). The clinical symptoms and manifestations of early lung cancer are often hidden and lack specificity; therefore, most patients are not diagnosed until the disease has reached an advanced stage (2). The recommended first-line therapy for advanced NSCLC (without driver oncogenes targetable by a tyrosine kinase inhibitor and exhibiting low programmed death ligand-1 expression), platinum-based doublet chemotherapy, has significantly improved the overall survival and quality of life for these patients $(3,4)$; however, after multiple cycles of chemotherapy, tumour cells can develop resistance to chemotherapeutic drugs, which lowers their activity against cancer cells (5). Moreover, the efficacy of chemotherapy is often limited by multidrug-resistance (MDR)-related proteins which extrude anticancer drugs (6). Therefore, investigating the molecular mechanisms underlying cisplatin resistance in NSCLC has been a focus of recent research $(7,8)$. Data from many studies show that the mechanism of MDR in tumours is mainly related to altered cell signaling through key proteins, such as phosphoinositide 3-kinase-Akt, Janus $\mathrm{N}$-terminal kinase and $\mathrm{Wnt} / \beta$-catenin (9-11). Accordingly, disrupting relevant signaling might be an efficient strategy for reversing acquired drug resistance. For example, microRNA (miR)-130a upregulation directly inhibits the expression of the tumour-suppressor 
gene runt-related transcription factor-3, leading to activation of Wnt/ $\beta$-catenin signaling and increased cisplatin resistance in hepatocellular carcinoma (12). Additionally, activation of the Wnt/ $\beta$-catenin signaling pathway due to cytoplasmic glycogen synthase kinase-3 $\beta$ (GSK-3 $\beta$ ) inhibition might explain cisplatin resistance observed in A549/cis-diamminedichloroplatinum (II) (DDP) cells (13). Furthermore, maternally expressed 3 and miR-130b were also shown to enhance cisplatin resistance by activating the $\mathrm{Wnt} / \beta$-catenin signaling pathway in lung cancer $(14,15)$. These findings suggest that $\mathrm{Wnt} / \beta$-catenin signaling might be closely related to cisplatin resistance.

Casein kinase II (CK2) is a highly conserved serine/threonine kinase commonly found in eukaryotic cells that most often exists as a tetrameric complex comprising of two catalytic subunits and two regulatory subunits $(16,17)$. CK2 exerts a variety of biological functions, including enhancing growth (18), angiogenesis (19), invasion and metastasis $(19,20)$ in various human tumour xenografts, including lung cancer (19), urothelial cancer (21), mesothelioma (22), hepatocellular cancer (23) and gastric cancer (24), as well as participating in the regulation of different signaling pathways. Previous findings suggested CK2 as a positive regulator of Wnt signaling $(25,26)$; however, to the best of our knowledge, its association with cisplatin resistance in lung cancer cells remains to be elucidated. Previous reports have indicated that the inhibition of dishevelled-2 (DVL-2; the most abundant isoform of the mammalian DVL family) can re-sensitize cisplatin-resistant lung cancer cells by downregulating Wnt/ $\beta$-catenin signaling $(27,28)$. Additionally, a study has shown that DVL-2 is phosphorylated by CK2 (29). In the present study the effect of CK2 on MDR in A549 lung cancer cells using A549/DDP cells as a model system was investigated. Initially, CK2 and DVL-2 levels in A549 and A549/DDP cells were determined, followed by western blot analysis to detect levels of MDR-related proteins, including multidrug-resistance-associated protein 1 (MPR1) and lung resistance protein (LRP), in A549/DDP cells in the presence or absence of CX4945 treatment. Thus, the aim of the present study was to investigate the effects of CX4945 on the cisplatin (DDP)-resistance of A549/DDP lung cancer cells and determine the underlying molecular mechanism.

\section{Materials and methods}

Cells and cell culture. The human lung adenocarcinoma cell line A549 and its cisplatin-resistant subline A549/DDP were obtained from the Institute of Cell Biology. Cells were cultured in a humidified incubator at $37^{\circ} \mathrm{C}$ and $5 \% \mathrm{CO}_{2}$ in Roswell Park Memorial Institute (RPMI)-1640 medium (Thermo Fisher Scientific, Inc.) supplemented with $10 \%$ heat-inactivated foetal bovine serum (Gibco; Thermo Fisher Scientific, Inc.), $100 \mathrm{U} / \mathrm{ml}$ penicillin and $100 \mu \mathrm{g} / \mathrm{ml}$ streptomycin (HyClone; GE Healthcare Life Sciences). To maintain drug resistance, A549/DDP cells were maintained in the presence of $0.5 \mu \mathrm{g} / \mathrm{ml}$ cisplatin (Merck KGaA).

Cell-proliferation analysis. The effect of cisplatin on cell growth was determined using Cell Counting Kit-8 (CCK-8; Dojindo Molecular Technologies Inc.) assays. For this, $100 \mu 1$ A549 and A549/DDP cell suspensions were distributed in quadruplicate in 96-well plates at a density of $5 \times 10^{4}$ cells/well. Culture medium $(100 \mu \mathrm{l})$ was added to the wells of 96-well plates as a blank control group, followed by incubation of both sets of plates at $37^{\circ} \mathrm{C}$ and $5 \% \mathrm{CO}_{2}$ for $24 \mathrm{~h}$. The cells were then treated with or without $15 \mu \mathrm{M}$ CX4945 (Selleck Chemicals Co., Ltd.) for $24 \mathrm{~h}$, followed by an additional $24 \mathrm{~h}$ incubation with $0,1.25,2.5,5,10$, or $20 \mu \mathrm{g} / \mathrm{ml}$ cisplatin. CCK-8 solution $(10 \mu \mathrm{l})$ was subsequently added to each well of the plates and incubated for $1 \mathrm{~h}$, after which the absorbance at $450 \mathrm{~nm}$ was measured. The proliferation of A549 and A549/DDP cells was also determined by the same method after cells were treated with cisplatin $(5 \mu \mathrm{g} / \mathrm{ml})$ for $0,12,24,36,48$ and $72 \mathrm{~h}$. This procedure was performed three times, and the mean value was calculated. The concentration at which cisplatin alone or in combination with CX4945 produced 50\% growth inhibition $\left(\mathrm{IC}_{50}\right)$ was calculated based on the relative survival curve.

Flow cytometric analysis of apoptosis. A total of $5 \times 10^{5}$ A549/DDP cells/well were cultured overnight in 6-well plates, followed by the addition of CX4945 at a concentration of 0,5 , $10,15,20$, or $25 \mu \mathrm{M}$. After $24 \mathrm{~h}$, after cells were digested with trypsin with no EDTA, they were centrifuged at $350 \times \mathrm{g}$ at $4^{\circ} \mathrm{C}$ for $5 \mathrm{~min}$, washed twice with phosphate-buffered saline, and resuspended in binding buffer (BD Biosciences) at a concentration of $2 \times 10^{5}$ cells $/ \mathrm{ml}$. Annexin V-conjugated fluorescein isothiocyanate and propidium iodide (BioLegend, Inc.) was added to the binding buffer and incubated for $15 \mathrm{~min}$ at room temperature. After incubation, the percentage of apoptotic cells was detected using a flow cytometer (BD FACSCalibur; BD Biosciences) and analysed usig FlowJO version 7.6.1 (Tree Star, Inc.). After dividing the A549/DDP cells into four groups based on different treatments (RPMI-1640, DDP alone, CX4949 alone, or combination treatment), apoptosis was detected using flow cytometry.

Western blot analysis. After the treatment with RPMI-1640 medium, CX4945, cisplatin or CX4945+cisplatin, and incubation for $24 \mathrm{~h}$, whole-cell lysates were harvested from A549 and A549/DDP cells using cell lysis buffer (Beyotime Institute of Biotechnology). The protein concentration was measured using a bicinchoninic acid assay, and equal quantities $(20 \mu \mathrm{g})$ of protein were resolved using SDS-PAGE with a $10 \%$ gel. After resolving, the proteins were transferring to polyvinylidene difluoride membranes. The membranes were blocked with $5 \%$ bovine serum albumin (Sigma-Aldrich; Merck KGaA) for $1 \mathrm{~h}$ at room temperature, and then incubated with a primary antibody overnight at $4^{\circ} \mathrm{C}$, followed by incubation with either horseradish peroxidase (HRP) conjugated goat anti-rabbit (cat. no. 111-035-003; 1:10,000) and goat anti-mouse secondary antibodies (cat. no. 115-035-003; 1:10,000) (both from Jackson ImmunoResearch Laboratories, Inc.) for $1 \mathrm{~h}$ at room temperature. Protein bands were detected using enhanced chemiluminescence reagents (EMD Millipore).

Antibodies against the following targets were used for western blot analysis: CK2 $\alpha$ (cat. no. sc-12738; 1:500; Santa Cruz Biotechnology, Inc.), $\beta$-catenin (cat. no. sc-7963; 1:500; Santa Cruz Biotechnology, Inc.), DVL-2 (cat. no. 373413;

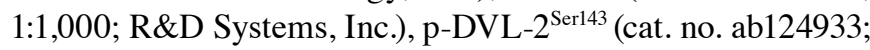
1:1,000; Abcam), p-DVL-2 ${ }^{\text {Thr224 }}$ (cat. no. ab124941; 1:1,000; Abcam), c-Myc (cat. no. 9402; 1:500; Cell Signaling 
Technology, Inc.), caspase-3 (cat. no. sc-271759; 1:500; Santa Cruz Biotechnology, Inc.), cleaved caspase-3 (cat. no. 9661; 1:500; Cell Signaling Technology, Inc.); cyclin D1 (cat. no. 2922; 1:500; Cell Signaling Technology, Inc.), MRP1 (cat. no. sc-365635; 1:1,000; Santa Cruz Biotechnology, Inc.) and LRP (cat. no. sc-390134; dilution, 1:500; Santa Cruz Biotechnology, Inc.). Densitometry analysis was performed using ImageJ version 1.52a (National Institutes of Health). The respective total protein was used as the loading control for phosphoproteins. $\beta$-actin was used as the loading control for all other proteins.

RNA extraction and quantitative reverse transcription polymerase chain reaction $(R T-q P C R)$. After the indicated treatments, total RNA was extracted from cells from the four groups (blank control, cisplatin alone, CX4945 alone and CX4945+cisplatin) using Trizol ${ }^{\circledR}$ (Thermo Fisher Scientific, Inc.) according to manufacturer instructions. Total RNA was reverse transcribed to cDNA at $42^{\circ} \mathrm{C}$ for $60 \mathrm{~min}$ followed by $72^{\circ} \mathrm{C}$ for $10 \mathrm{~min}$, using a PrimeScript RT reagent kit (Bio-Rad Laboratories, Inc.). qPCR was conducted using the UltraSYBR reagent $(\mathrm{CWBIO}$, Technology, Co. Ltd.) on a thermocycler with the following cycling conditions: Initial denaturation for $3 \mathrm{~min}$ at $94^{\circ} \mathrm{C}$, followed by 40 cycles of denaturation for $30 \mathrm{sec}$ at $94^{\circ} \mathrm{C}$, annealing for $30 \mathrm{sec}$ at $60^{\circ} \mathrm{C}$, extension for $30 \mathrm{sec}$ at $72^{\circ} \mathrm{C}$, and a final extension step for 2 min at $72^{\circ} \mathrm{C}$. Primer sequences are listed in Table I. The RNA levels of target genes were standardized against that of $\beta$-actin using the $2^{-\Delta \Delta C q}$ method (30). All assays were performed in triplicate to ensure minimum deviation.

Statistical analysis. Statistical analysis was performed using GraphPad Prism software (v5.01; GraphPad Software, inc.). Data are expressed as the mean \pm standard deviation. Independent samples t-tests and paired t-tests were used to compare data between two groups. One-way analysis of variance with Bonferroni's correction was used to compare data among three or more groups. A $\mathrm{P}<0.05$ was considered to indicate a statistically significant difference.

\section{Results}

Effects of cisplatin on A549 and A549/DDP cell growth. A549 and A549/DDP cells were treated with cisplatin at increasing concentrations $(0,1.25,2.5,5,10$ or $20 \mu \mathrm{g} / \mathrm{ml})$, and the viability of treated cells was detected using CCK- 8 assays. The viability of the cells was also determined by the same method after treatment with cisplatin $(5 \mu \mathrm{g} / \mathrm{ml})$ for $0,12,24,36,48$ and $72 \mathrm{~h}$. Cisplatin significantly inhibited A549 and A549/DDP cell growth in a dose- and time-dependent manner (Fig. 1A and C), with $\mathrm{IC}_{50}$ values for cisplatin of $3.74 \pm 0.22$ and $19.28 \pm 2.17 \mu \mathrm{g} / \mathrm{ml}$ in A549 and A549/DDP cells, respectively ( $\mathrm{P}=0.0002$; Fig. 1B). These results indicated that A549/DDP cells were 5.16-fold more resistant to cisplatin compared with that of A549 cells. Moreover, A549/DDP cell viability decreased until the concentration increased to $5 \mu \mathrm{g} / \mathrm{ml}$; therefore, we chose this as the optimal concentration for treatment.

Levels of Wnt-signaling-pathway-related proteins and resistance-related proteins in A549 and A549/DDP cells.
Table I. Primer sequences used in the present study.

\begin{tabular}{ll}
\hline Primer name & \multicolumn{1}{c}{ Sequence } \\
\hline DVL-2 & \\
Forward & 5'-GAGGAAGAGACTCCCTACCTG-3' \\
Reverse & 5'-CGGGCGTTGTCATCTGAAAT-3' \\
3-catenin & \\
Forward & 5'-CATCTACACAGTTTGATGCTGCT-3' \\
Reverse & 5'-GCAGTTTTGTCAGTTCAGGGA-3' \\
C-myc & \\
Forward & 5'-GTCAAGAGGCGAACACACAAC-3' \\
Reverse & 5'-TTGGACGGACAGGATGTATGC-3' \\
Cyclin D1 & \\
Forward & 5'-GCTGCGAAGTGGAAACCATC-3' \\
Reverse & 5'-CCTCCTTCTGCACACATTTGAA-3' \\
MRP1 & \\
Forward & 5'-AAGGAGGTACTAGGTGGGCTT-3' \\
Reverse & 5'-CCAGTAGGACCCTTCGAGC-3' \\
LRP & \\
Forward & 5'-TACATCCGGCAGGACAATGAG-3' \\
Reverse & 5'-CTGTGCAGTAGTGACGTGGG-3' \\
Caspase-3 & 5'-CATGGAAGCGAATCAATGGACT-3' \\
Forward & 5'-CTGTACCAGACCGAGATGTCA-3' \\
Reverse &
\end{tabular}

DVL-2, dishevelled-2; MRP1, multidrug resistance-associated protein 1; LRP, lung resistance protein.

Activation of $\mathrm{Wnt} / \beta$-catenin signaling not only leads to a variety of human diseases (31) but it is also associated with cisplatin resistance (13). CK2 and DVL-2 participate in and activate Wnt/ $\beta$-catenin signaling $(26,32)$. Moreover, S143 and T224 of human DVL-2 are phosphorylated by CK1 $/ \varepsilon$, and the S143A mutation inhibits polo-box domain (PB)-DVL-2 interaction, while the T224A mutation partially inhibits this interaction (33). The phosphorylation of DVL-2 and DVL-2-PBD binding are critical for subsequent interaction with polo-like kinase 1 , which is involved in non-canonical Wnt signaling (33). However, whether these two phosphorylation sites are associated with the canonical Wnt signaling pathway remains unclear. Therefore, to determine whether differences in responses to cisplatin between A549 and A549/DDP cells were related to disparities in CK2 and DVL-2 levels, western blot analysis was performed to evaluate CK2, total-DVL-2, p-DVL-2 ${ }^{\text {Ser143 }}$ and p-DVL-2 ${ }^{\text {Thr224 }}$ levels in both cell lines. As shown in Fig. 2, CK2 and p-DVL-2 $2^{\text {Ser143 }}$ expression levels were significantly higher in A549/DDP cells compared with the A549 cells $(\mathrm{P}<0.001)$. Additionally, $\beta$-catenin levels were significantly higher in A549/DDP cells $(\mathrm{P}<0.001)$, as were c-Myc and cyclin D1 $(\mathrm{P}<0.001)$, which are direct targets of lymphoid-enhancer-binding factor/T cell factor (LEF/TCF) transcription factors and function downstream of Wnt signaling (34). However, the levels of total DVL-2 and p-DVL-2 ${ }^{\text {Thr224 }}$ in A549 and A549/DDP cells were not significantly different (Fig. 2A and B). To further investigate whether the resistance of A549/DDP was 

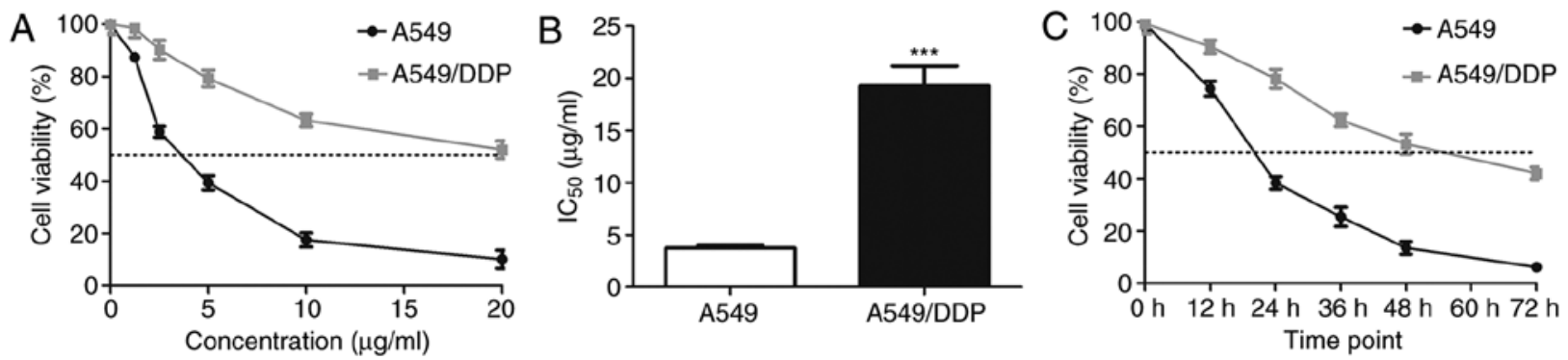

Figure 1. Effect of cisplatin on A549 and A549/DDP cell proliferation. (A) A549 and A549/DDP cells were treated with 0, 1.25, 2.5, 5, 10, or 20 $\mu \mathrm{g} / \mathrm{ml}$ cisplatin for $24 \mathrm{~h}$, and cell viability was detected using performing CCK-8 assays. (B) $\mathrm{IC}_{50}$ value of cisplatin in A549 and A549/DDP cells (mean \pm standard deviation; $\mathrm{n}=3) .{ }^{* * *} \mathrm{P}<0.001$ vs. A549 cells. Statistical analysis was performed using independent samples t-tests. (C) A549 and A549/DDP cells were treated with cisplatin $(5 \mu \mathrm{g} / \mathrm{ml})$ for $0,12,24,36,48$ and $72 \mathrm{~h}$ and cell viability was analysed using CCK-8 assay. CCK-8, Cell Counting Kit-8; DDP, cis-diamminedichloroplatinum (II).

A

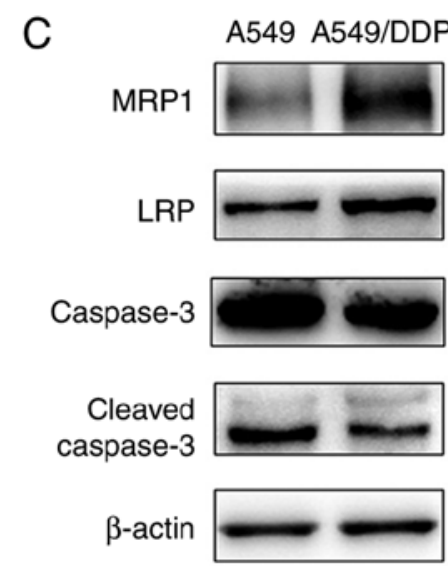

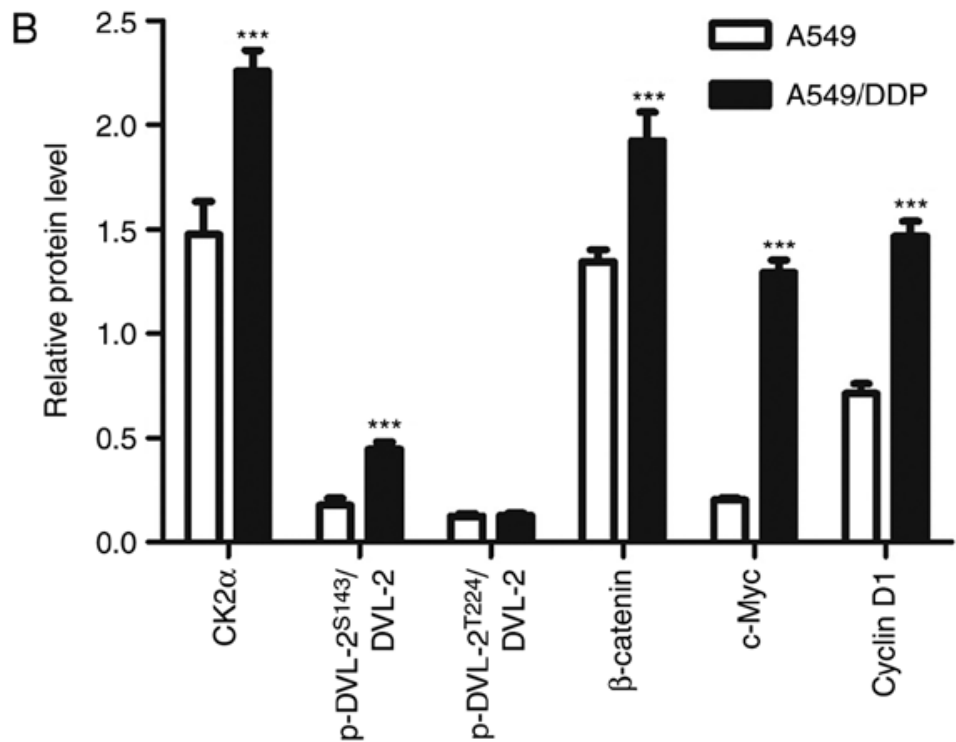

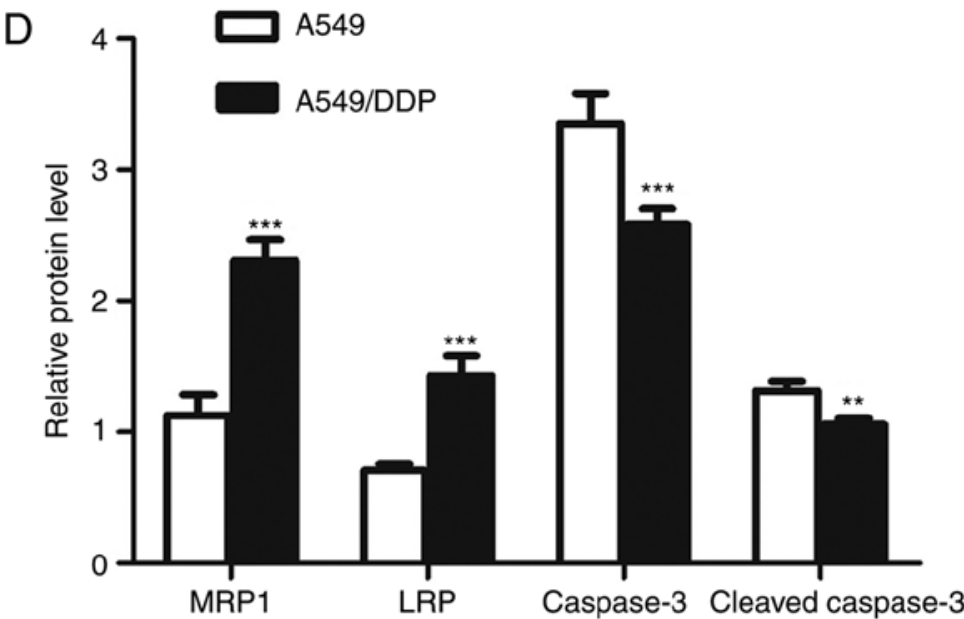

Figure 2. Expression of proteins associated with Wnt signaling and drug resistance, respectively, in A549 and A549/DDP cells. (A and C) Western blot analyses using $\beta$-actin as an internal control. Relative protein levels (mean \pm standard deviation; $n=3$ ) associated with the (B) Wnt signaling pathway and (D) cisplatin resistance, in A549 and A549/DDP cells. ${ }^{* *} \mathrm{P}<0.01,{ }^{* * * *} \mathrm{P}<0.001$ vs. A549 cells. Statistical analysis was performed using independent samples t-tests. DDP, cis-diamminedichloroplatinum (II); DVL-2, dishevelled-2; p, phosphorylated; CK2, casein kinase II; MRP1, multidrug resistance-associated protein 1; LRP, lung resistance protein.

associated with resistance-related proteins, levels of MRP1, LRP, caspase-3 and cleaved-caspase-3 were analyzed using western blot, revealing significantly higher MRP1 and LRP levels $(\mathrm{P}<0.001)$ and lower caspase-3 $(\mathrm{P}<0.001)$ and cleaved caspase-3 $(\mathrm{P}<0.001)$ levels in A549/DDP cells compared with that in A549 cells (Fig. 2C and D). These results suggested 
A

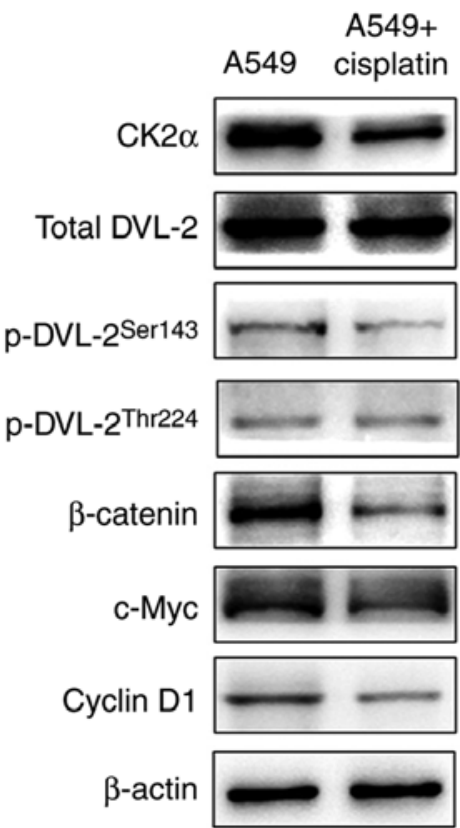

C

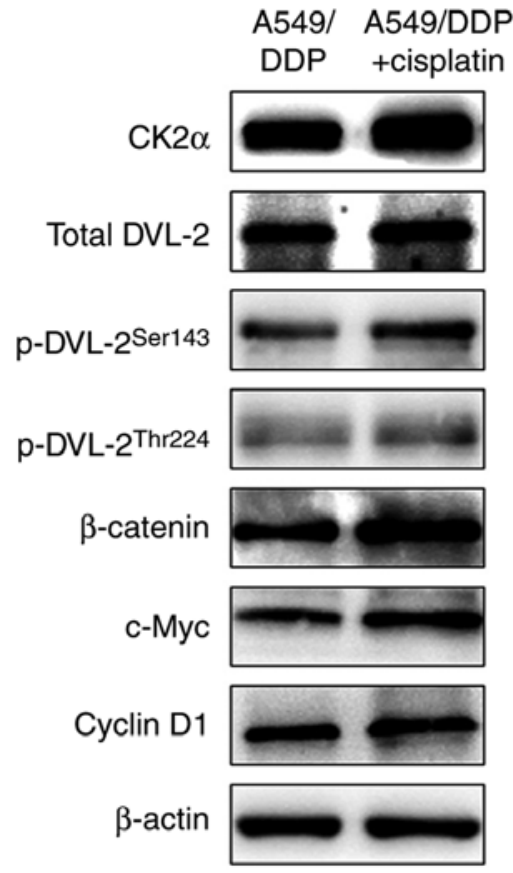

B

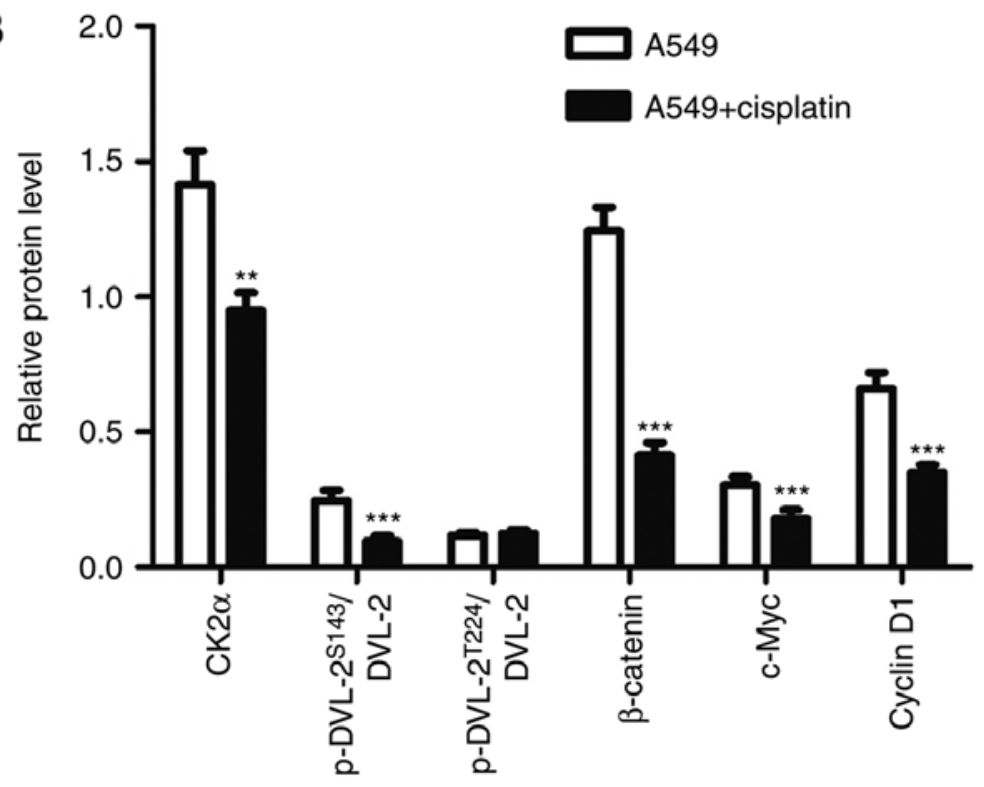

D

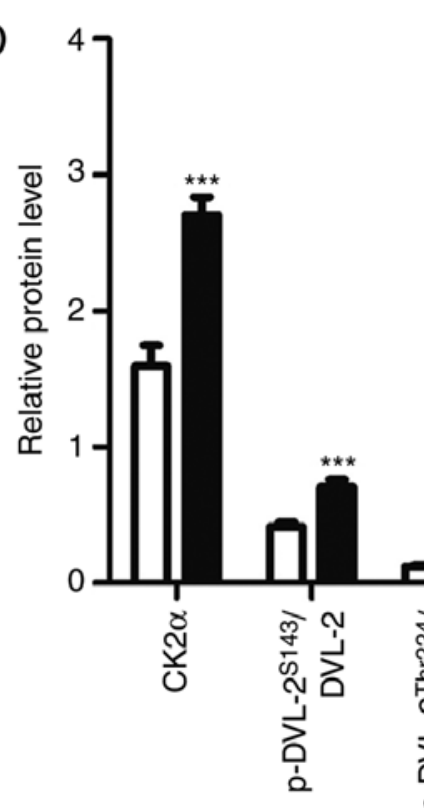

A549/DDP

A549/DDP+cisplatin

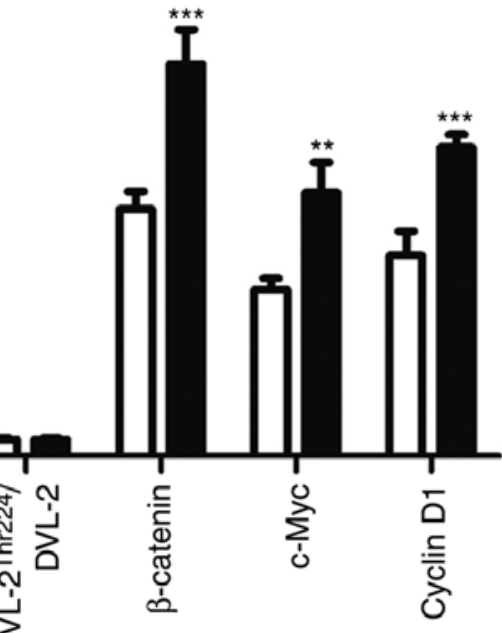

Figure 3. Expression of CK2, DVL-2, $\beta$-catenin, c-Myc and cyclin D1 in A549 and A549/DDP cells before and after cisplatin treatment. (A and C) Western blot analyses using $\beta$-actin as an internal control. (B and D) Relative protein levels (mean \pm standard deviation; $\mathrm{n}=3$ ) of CK2, DVL-2, $\beta$-catenin, c-Myc and cyclin D1 were determined in A549 and A549/DDP cells. ${ }^{* *} \mathrm{P}<0.01,{ }^{* * *} \mathrm{P}<0.001$ vs. A549 cells and A549/DDP cells before cisplatin treatment. Statistical analysis was performed using paired t-tests. CK2, casein kinase II; DVL-2, dishevelled-2; DDP, cis-diamminedichloroplatinum (II).

that differences in cisplatin resistance between A549 cells and A549/DDP cells might be associated with upregulated levels of MRP1, LRP, CK2 and p-DVL-2 $2^{\text {Ser143 }}$, which are important proteins associated with the $\mathrm{Wnt} / \beta$-catenin pathway.

Effects of cisplatin on Wnt-signaling-pathway and resistance-related proteins in A549 and A549/DDP cells. Previous studies have not addressed DVL-mediated regulation of cancer cell resistance to chemotherapy. To investigate whether cisplatin resistance in lung adenocarcinoma cells is associated with DVL-2 activity, total DVL-2, p-DVL-2 ${ }^{\text {Ser143 }}$ and p-DVL-2 ${ }^{\text {Thr224 }}$ levels were detected after cisplatin treatment of A549 and A549/DDP cells. No changes in total DVL-2 or p-DVL-2 ${ }^{\text {Thr224 }}$ levels were found upon cisplatin treatment in either cell line; however, cisplatin treatment increased levels of CK2 and p-DVL-2 ${ }^{\text {Ser143 }}$ in A549/DDP cells but decreased these levels in A549 cells. Additionally, $\beta$-catenin, c-Myc and cyclin D1 levels were associated with CK2 levels in A549 and A549/DDP cells (Fig. 3). A previous study showed that the upregulated expression of $\beta$-catenin, cyclin D1 and c-Myc resulted in the activation of the $\mathrm{Wnt} / \beta$-catenin pathway (35); therefore, it was hypothesized that cisplatin activates 
A

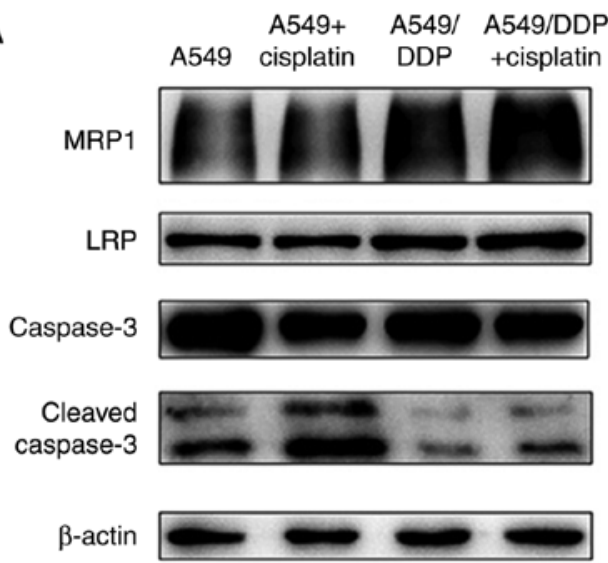

B

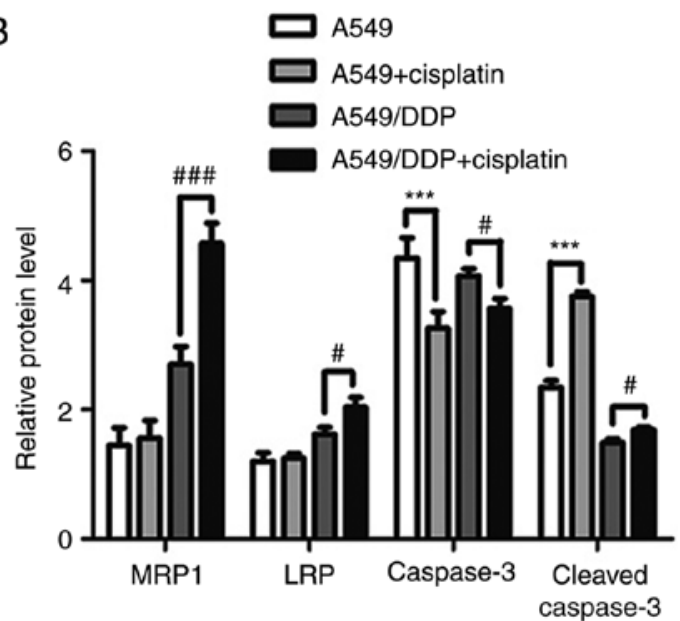

Figure 4. Expression of MRP1, LRP, caspase-3 and cleaved caspase-3 in A549 and A549/DDP cells before and after cisplatin treatment. (A) Western blot analyses using $\beta$-actin as an internal control. (B) Relative protein levels (mean \pm standard deviation; $n=3$ ) of MRP1, LRP, caspase-3 and cleaved caspase-3 were determined in A549 and A549/DDP cells. ${ }^{* * *} \mathrm{P}<0.001$ vs. A549 cells before cisplatin treatment. ${ }^{\#} \mathrm{P}<0.05$, ${ }^{\# \#} \mathrm{P}<0.001$ vs. A549/DDP cells before cisplatin treatment. Statistical analysis was performed using paired t-tests. MRP1, multidrug resistance-associated protein 1; LRP, lung resistance protein; DDP, cis-diamminedichloroplatinum (II).

Wnt/ $\beta$-catenin signaling in A549/DDP cells, which might be related to upregulated CK2 and p-DVL-2 ${ }^{\text {Ser143 }}$ levels. Moreover, previous studies suggest that the mechanisms associated with cancer drug resistance are closely related to resistance proteins and apoptosis (36-38). Therefore, MRP1 and LRP levels were analyzed after cisplatin treatment of A549 and A549/DDP cells, which revealed significantly higher levels of these markers in A549/DDP cells $(\mathrm{P}<0.001)$, whereas they were unchanged in A549 cells $(\mathrm{P}<0.001)$. Furthermore, the levels of caspase-3 decreased and the levels of cleaved caspase- 3 increased in both cell lines following cisplatin treatment compared with no cisplatin treatment $(\mathrm{P}<0.001)$, but this upregulation was more significant in A549 cells compared with that the A549/DDP cells (Fig. 4).

Effects of CX4945 on apoptosis and resistance-related proteins in A549/DDP cells. To assess the effects of CX4945 on apoptosis, A549/DDP cells were exposed to increasing concentrations of CX4945 $(0,5,10,15,20$, or $25 \mu \mathrm{M})$ for $24 \mathrm{~h}$, followed by flow cytometric analysis. Initially, the proportions of apoptotic cells increased from 4.78 to $5.69 \%, 6.08$ and $6.87 \%$ after treatment with 5, 10 and $15 \mu \mathrm{M}$ CX4945, respectively; however, this percentage increased markedly to $13.59 \%$ at a CX4945 concentration of $20 \mu \mathrm{M}$ (Fig. 5A). Western blot analysis of similarly treated A549/DDP cells for proteins associated with drug resistance revealed decreasing levels of MRP1 and LRP with increasing CX4945 concentrations (Fig. 5B); however, levels of caspase-3 decreased and cleaved-caspase-3 increased notably up until a CX4945 concentration of $20 \mu \mathrm{M}$, consistent with the flow cytometry data. Therefore, according to a previous finding (39) and these results, $15 \mu \mathrm{M}$ (as apoptosis only increased at concentrations $<20 \mu \mathrm{M}$ ) and $24 \mathrm{~h}$ was chosen as the optimal concentration and time for pretreatment.

CX4945 increased cisplatin sensitivity and cisplatin-induced apoptosis in A549/DDP cells. To investigate whether CX4945 affects the proliferation of A549/DDP cells, they were incubated with different concentrations of cisplatin $(0,1.25,2.5$,
5,10 , or $20 \mu \mathrm{g} / \mathrm{ml}$ ) in the presence or absence of CX4945 $(15 \mu \mathrm{M})$ for $24 \mathrm{~h}$, followed by assessment of cell viability using CCK-8 assay. The $\mathrm{IC}_{50}$ value for cisplatin in CX4945 treated cells was lower compared with that for parental A549/DDP cells $(6.43 \pm 0.32$ vs. $18.43 \pm 1.56 \mu \mathrm{g} / \mathrm{ml}$, respectively) (Fig. 6A), indicating that CX4945 treatment increased the cisplatin sensitivity of A549/DDP cells. To confirm that CX4945 enhances cisplatin-mediated apoptosis, flow cytometry was performed to detect apoptosis in A549/DDP cells treated with RPMI-1640 (as a blank control group), CX4945, cisplatin, or CX4945+cisplatin. The results revealed that total apoptotic rates in groups treated with CX4945, cisplatin, or CX4945+cisplatin were $8.62 \pm 0.43 \%$ (compared with the control group; $\mathrm{P}<0.05$ ), $9.64 \pm 0.38 \%$ (compared with the control group; $\mathrm{P}<0.05$ ) or $18.54 \pm 0.74 \%$ (compared with the control group; $\mathrm{P}<0.05)$, which were higher compared with that of the control group $(8.05 \pm 0.36 \%)$. Furthermore, the apoptotic rate in the combination treatment group $(18.54 \pm 0.74 \%)$ was significantly higher compared with that in the groups treated with CX4945 alone $(8.65 \pm 0.43 \%)$ compared with CX4945+cisplatin group $(\mathrm{P}<0.001)$, or cisplatin alone $(9.64 \pm 0.38 \%)$ compared with CX4945+cisplatin group $(\mathrm{P}<0.001$; Fig. 6B). These data indicated that inhibition of CK2 activity by CX4945 enhanced cisplatin-induced apoptosis in A549/DDP cells.

CX4945 reversed cisplatin resistance by blocking Wnt/ $\beta$-catenin signaling in A549/DDP cells. The present study revealed that cisplatin can lead to the activation of Wnt/ $\beta$-catenin signaling, which might be associated with CK2 and $\mathrm{p}-\mathrm{DVL}-2^{\text {Ser143 }}$ upregulation. To supporting this finding, A549/DDP cells were treated with RPMI-1640, CX4945, cisplatin, or CX4945+cisplatin, followed by detection of mRNA and protein levels of Wnt signaling-related molecules using RT-qPCR and western blot analysis, respectively. p-DVL-2 ${ }^{\text {Ser143 }}, \beta$-catenin, c-Myc and cyclin D1 mRNA and protein levels decreased significantly in the combined treatment group compared with cisplatin treatment alone, whereas 


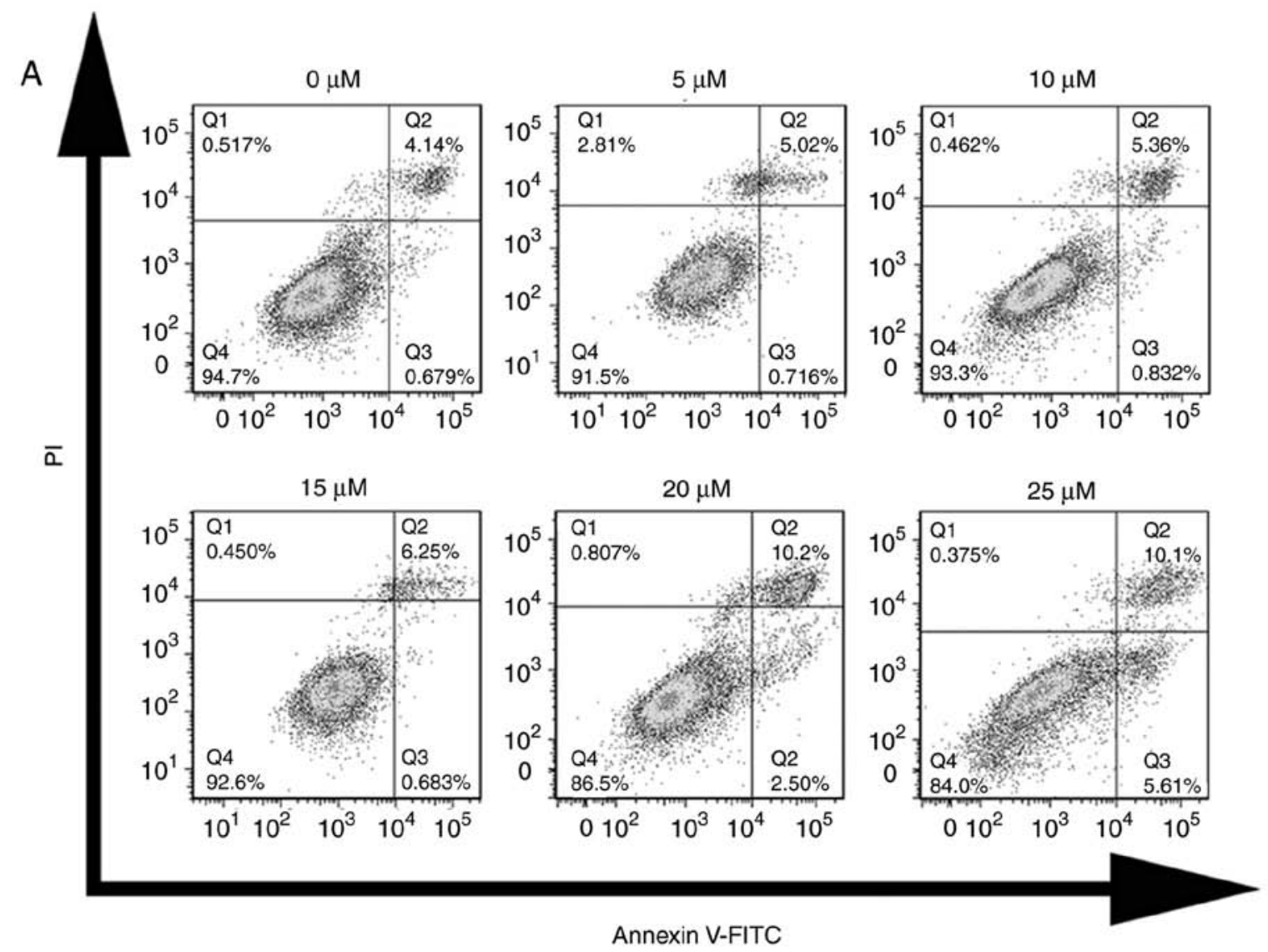

B
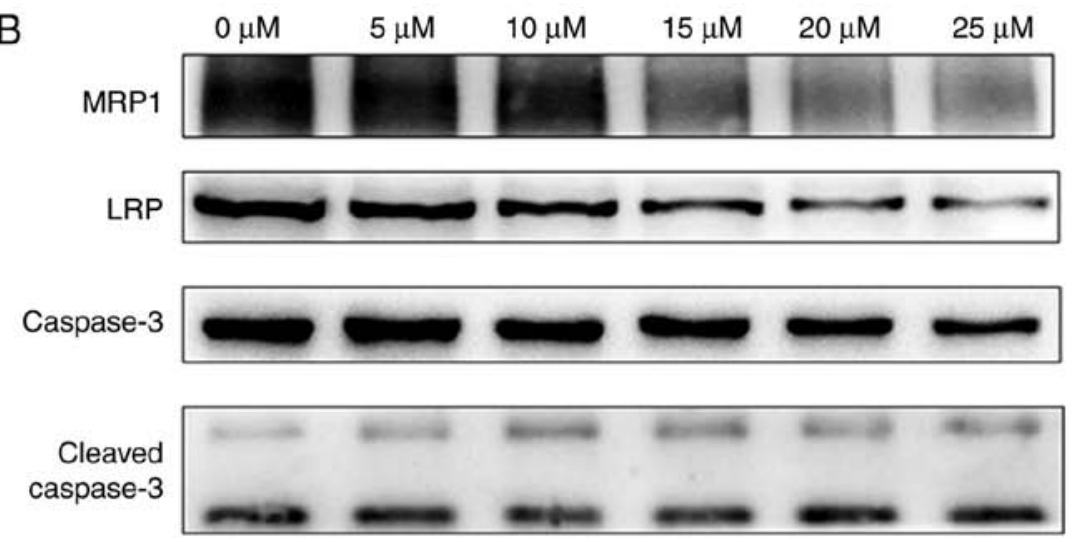

$\beta$-actin

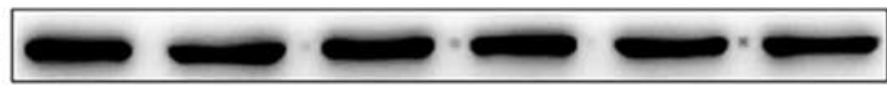

Figure 5. Effects of CX4945 on apoptosis- and drug resistance-related proteins in A549/DDP cells. (A) Flow cytometric analysis of apoptosis in A549/DDP cells treated with $0,5,10,15,20$, or $25 \mu \mathrm{M} \mathrm{CX} 4945$ for $24 \mathrm{~h}$. (B) Protein levels of MRP1, LRP, caspase-3 and cleaved caspase-3 in response to different concentrations of CX4945 in A549/DDP cells. MRP1, multidrug resistance-associated protein 1; LRP, lung resistance protein; DDP, cis-diamminedichloroplatinum (II); PI, propidium iodide.

total DVL-2 and p-DVL-2 ${ }^{\text {Thr224 }}$ levels did not differ significantly among the groups $(\mathrm{P}>0.05)$. Similar results were obtained upon comparison of CX4945 only group with the control group (Fig. 7A-D). These results revealed that inhibition of CK2 activity decreased p-DVL- $2^{\text {Ser143 }}$ levels and implied that DVL-2 phosphorylation at Ser143 by CK2 promotes activation of $\mathrm{Wnt} / \beta$-catenin signaling.

Additionally, MRP1, LRP, caspase-3 and cleaved-caspase-3 protein and mRNA levels were analyzed, and revealed that
MRP1, LRP and caspase-3 levels in the combined-treatment group were significantly lower compared with that in the cisplatin-only group $(\mathrm{P}<0.01)$, whereas cleaved-caspase-3 levels were significantly upregulated in the combined-treatment group $(\mathrm{P}<0.001)$. Moreover, compared with that in the control group, MRP1 and LRP mRNA and protein levels decreased in the CX4945-only group, whereas caspase-3 mRNA and protein levels and cleaved-caspase- 3 protein levels remained virtually unchanged between both groups. Levels of MRP1, LRP 

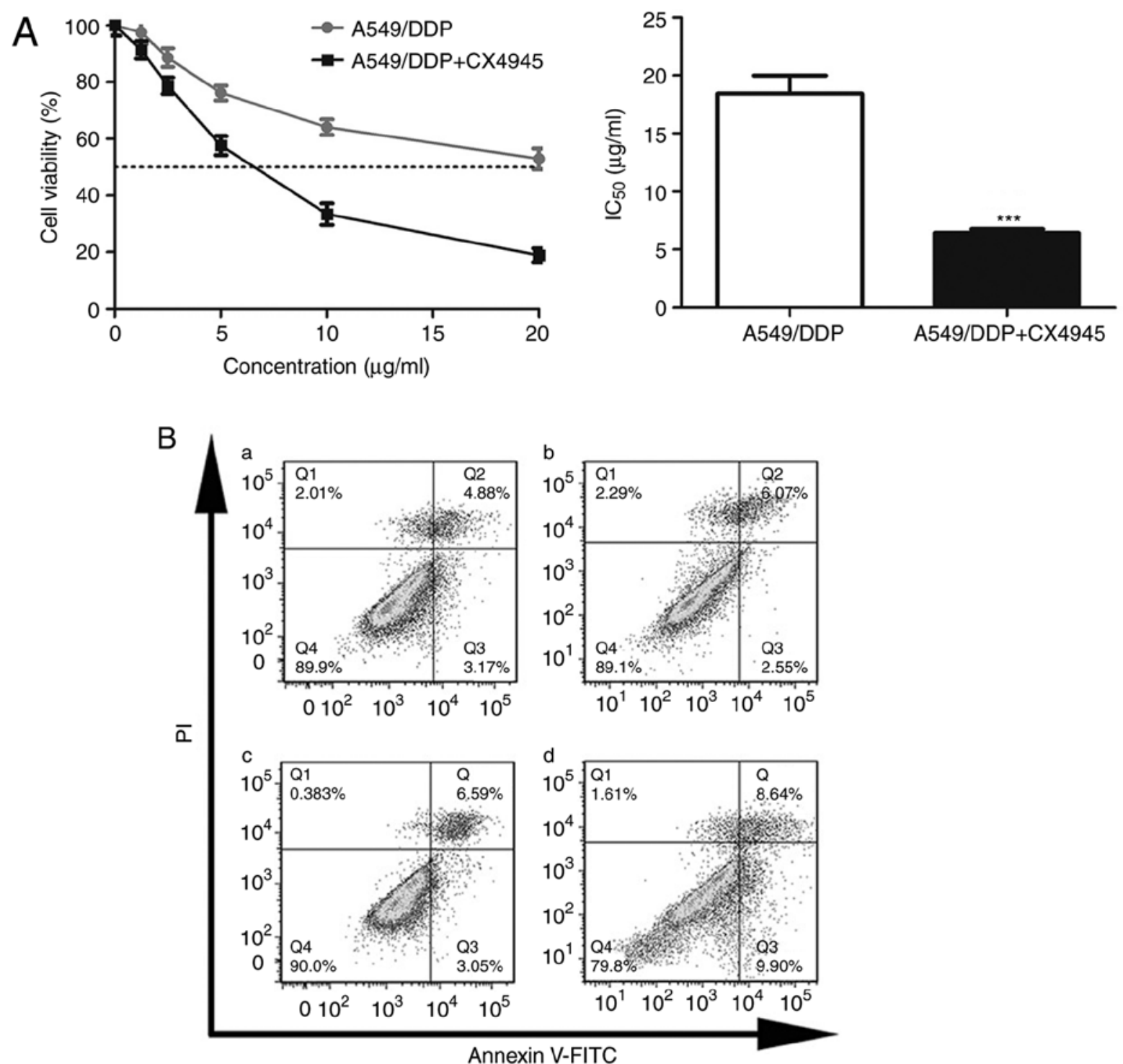

Figure 6. Effect of CX4945 on the proliferation and apoptosis of A549/DDP cells. (A) After pre-treatment with CX4945 for 24 h, A549/DDP cells were treated with $0,1.25,2.5,5,10$, or $20 \mu \mathrm{g} / \mathrm{ml}$ cisplatin for $24 \mathrm{~h}$, and the $\mathrm{IC}_{50}$ values of cisplatin in A549/DDP cells were determined (mean \pm standard deviation; $\mathrm{n}=3$ ). ${ }^{* * *} \mathrm{P}<0.001$ vs. A549/DDP cells without CX4945 pre-treatment. Statistical analysis was performed using independent samples t-tests. (B) A549/DDP cells were treated with (Ba) RPMI-1640 medium (blank control), (Bb) CX4945, (Bc) cisplatin, or (Bd) CX4945+cisplatin and incubated for $24 \mathrm{~h}$. Apoptotic cells were analysed by flow cytometry. DDP, cis-diamminedichloroplatinum (II); PI, propidium iodide; $\mathrm{IC}_{50}, 50 \%$ growth inhibition.

and caspase-3 mRNA are consistent with their protein levels (Fig. 8A-C). These results indicated that CX4945 reversed cisplatin resistance by blocking Wnt/ $\beta$-catenin signaling, downregulating levels of resistance-associated proteins, and inducing apoptosis.

\section{Discussion}

Platinum drugs alone or in combination with other drugs are considered the standard first-line chemotherapy for patients with advanced lung cancer (3). However, intrinsic and acquired resistance to cisplatin is a major obstacle for the clinical treatment of NSCLC. The mechanism of drug resistance in lung cancer is very complex, and many factors are involved. First, studies identified mechanisms associated with membrane-transport protein-mediated drug efflux pumps and associated with upregulation of membrane proteins with efflux functions, such as P-glycoprotein, MRP and LRP $(38,40)$. Second, abnormal activation of intracellular enzyme systems, such as topoisomerase (Topo) and glutamyl transpeptidase, can combine with various chemotherapeutic drug, such as platinum compounds, melphalan, cyclophosphamide, chlorambucil, doxorubicin and nitrogen mustards to reduce their activity (41). For example, decreased DNA Topo II expression can cause tumour cells to rapidly repair DNA and evade DNA-targeted chemotherapeutics, thereby mediating drug resistance (42). Third, upregulation of antiapoptotic markers, such as B-cell lymphoma-2 and c-Myc, can lead to a decrease in cancer cell apoptosis (43).

Cisplatin is the most commonly used chemotherapeutic drug and causes tumour cell death by disrupting DNA structure and function (44). Therefore, we hypothesized that cisplatin resistance might be related to the aberrant expression of signaling molecules induced by DNA destruction, resulting 
A

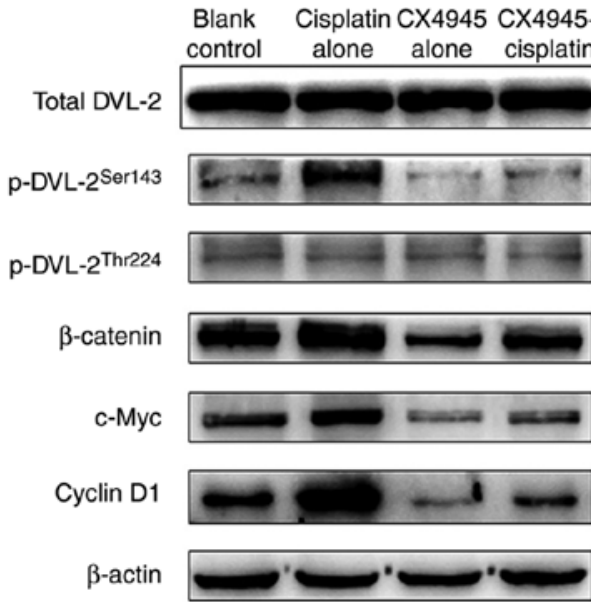

B

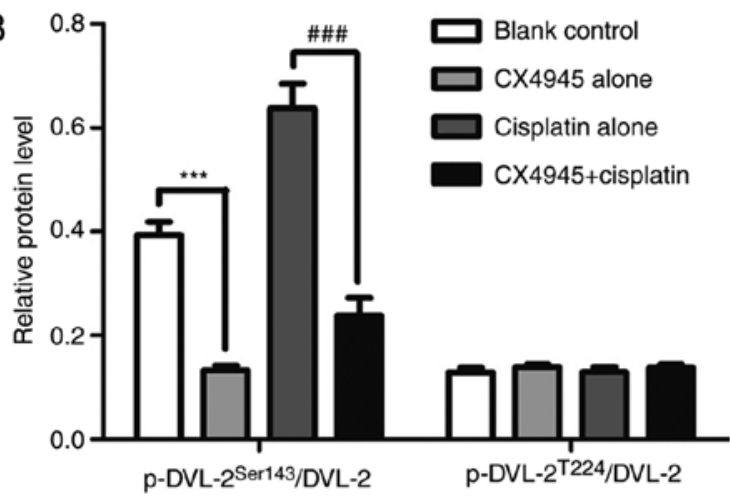

D

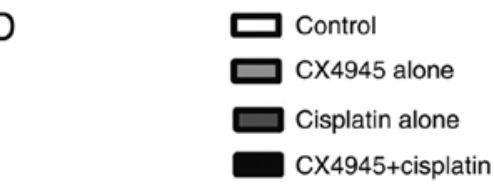

C
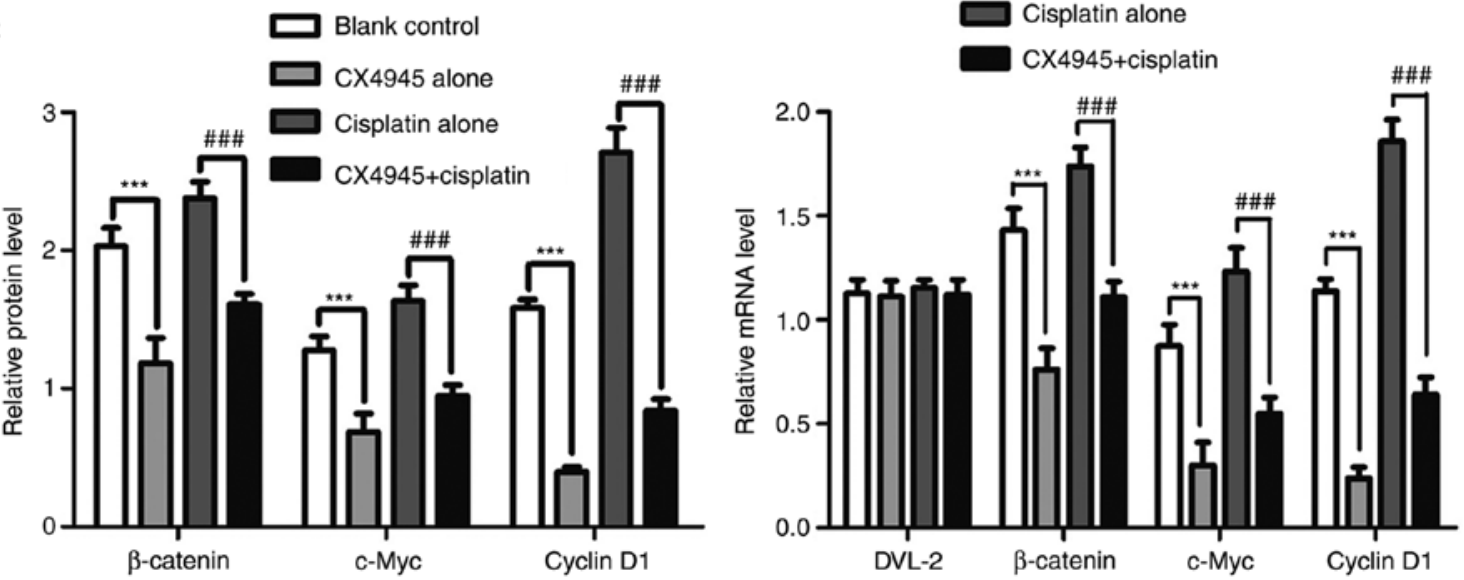

Figure 7. Protein and mRNA levels of DVL-2, $\beta$-catenin, c-Myc and cyclin D1 in A549/DDP cells treated with RPMI-1640, CX4945, cisplatin, or CX4945+cisplatin. RPMI-1640 served as the blank control. (A) Western blot analyses using $\beta$-actin as an internal control. Relative protein expression levels of (B) DVL-2, (C) $\beta$-catenin, c-Myc and cyclin D1 based on densitometry analysis of (A). (D) mRNA expression of DVL2, $\beta$-catenin, c-Myc and cyclin D1 determined using reverse transcription-quantitative PCR. Data represent the mean \pm standard deviation of three independent experiments and one-way analysis of variance. ${ }^{* * *} \mathrm{P}<0.001$ vs. blank control group; ${ }^{\# \# \#} \mathrm{P}<0.001$ vs. the cisplatin only group. DDP, cis-diamminedichloroplatinum (II); DVL-2, dishevelled-2.
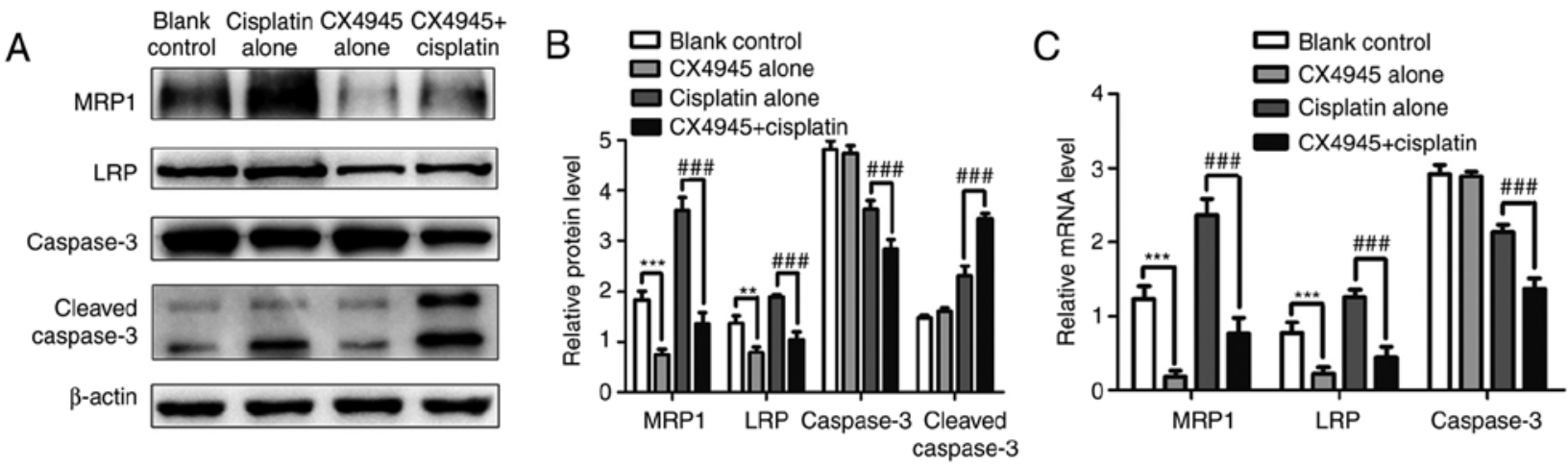

Figure 8. Protein and mRNA levels of MRP1, LRP and cleaved caspase-3 in A549/DDP cells treated with RPMI-1640, CX4945, cisplatin, or CX4945+cisplatin . RPMI-1640 served as the blank control. (A) Western blot analyses using $\beta$-actin as an internal control. (B) Relative protein expression levels based on densitometry analysis pf (A). (C) mRNA expression of MRP1, LRP and caspase-3 determined using reverse transcription-quantitative PCR. Data are presented as the mean \pm standard deviation of three independent experiments and one-way analysis of variance. ${ }^{*} \mathrm{P}<0.01,{ }^{* * * *} \mathrm{P}<0.001 \mathrm{vs}$. blank control group; ${ }^{* \# \#} \mathrm{P}<0.001$ vs. cisplatin only group. MRP1, multidrug resistance-associated protein 1; LRP, lung resistance protein; DDP, cis-diamminedichloroplatinum (II).

in altered activation of associated pathways. Activation of the Wnt/ $\beta$-catenin pathway leads to cisplatin resistance in lung cancer (13-15). Moreover, CK2 is a positive regulator of
Wnt signaling $(25,26)$. Therefore, we hypothesized that Wnt signaling might be associated with cisplatin resistance in lung cancer cells; however, the role of CK2 in cisplatin resistance 
in lung cancer cells, as well as the potential underlying mechanism, remained unknown. To the best of our knowledge, this is the first study investigating an association between CK2 and cisplatin resistance. The results from the present study showed that levels of CK2, p-DVL- $2^{\text {Ser143 }}, \beta$-catenin, cyclin D1 and c-Myc were significantly higher in A549/DDP cells compared with that in A549 cells, whereas no differences were observed in total DVL-2 and p-DVL-2 $2^{\text {Thr224 }}$ levels. Furthermore, significantly higher levels of MRP1 and LRP were found in A549/DDP cells compared with that in A549 cells, although the level of cleaved caspase-3 was significantly lower in A549/DDP cells. As well-established components of $\mathrm{Wnt} / \beta$-catenin signaling, upregulated $\beta$-catenin, cyclin D1 and c-Myc represent an activated state (or 'on-state') of this pathway (35). Therefore, the differences between A549 cells and A549/DDP cells in terms of cisplatin resistance might be connected to CK2 and p-DVL-2 ${ }^{\text {Ser143 }}$ upregulation and activation of Wnt signaling.

Previous studies show that the co-receptor LRP5/6 forms a complex with Wnt-bound Frizzled in the presence of a Wnt ligand (on-state), leading to the activation of DVL proteins via sequential phosphorylation, which displaces GSK-3 $\beta$ from the adenomatous polyposis coli/axin/GSK-3 $\beta$ complex $(35,45,46)$. Destruction of this complex stabilizes $\beta$-catenin, which accumulates in the cytoplasm and results in its subsequent translocation to the nucleus, where it binds $\mathrm{LEF} / \mathrm{TCF}$ transcription factors to activate the expression of c-Myc and cyclin D1 (45). DVL-2 participates in and activates $\mathrm{Wnt} / \beta$-catenin signaling (32); however, the mechanism associated with DVL phosphorylation during Wnt/ $\beta$-catenin signaling remains unclear. To investigate whether CK2 and p-DVL-2 ${ }^{\text {Ser143 }}$ are associated with cisplatin resistance, similar analyses was performed in the presence of this drug, finding that following cisplatin treatment, CK2 and p-DVL-2 $2^{\text {Ser143 }}$ levels in A549/DDP cells significantly increased while they were significantly reduced in A549 cells. However, no significant changes were observed in total DVL-2 and p-DVL-2 ${ }^{\mathrm{Thr} 224}$ levels upon cisplatin treatment of either A549/DDP or A549 cells. Additionally, cisplatin treatment significantly increased $\beta$-catenin, cyclin D1 and c-Myc levels in A549/DDP cells but significantly downregulated these markers in A549 cells. These data revealed a positive association between activation of Wnt/ $\beta$-catenin signaling and CK2 upregulation in A549/DDP cells. Furthermore, MRP1 and LRP protein levels were significantly upregulated after cisplatin treatment in A549/DDP cells; however, these levels remained unchanged in A549 cells. Furthermore, cleaved-caspase-3 levels increased significantly in both cell lines after cisplatin treatment, although their upregulation in A549/DDP cells was not as significant relative to that in A549 cells. Based on these results, we hypothesized that cisplatin activates $\mathrm{Wnt} / \beta$-catenin signaling by upregulating CK2 in A549/DDP cells but inactivates this pathway in A549 cells. Moreover, DVL-2 phosphorylation at Ser143 by CK 2 might account for the activation of $\mathrm{Wnt} / \beta$-catenin signaling, which was also accompanied by MRP1 and LRP upregulation.

CX4945 is a potent and selective ATP-competitive inhibitor of CK2 (47) and reportedly inhibits not only the migration and invasion of A549 cells $(39,48)$ but also suppresses cell growth through induction of cell cycle arrest at the $\mathrm{G}_{2} / \mathrm{M}$ phase and apoptosis (49). To address our hypothesis regarding cisplatin resistance, A549/DDP cells were divided into four groups, and similar analyses were performed, revealing significantly decreased p-DVL- $2^{\text {Ser143 }}$ levels in the combined treatment group compared with that in the cisplatin only group and accompanied by the inactivation of $\mathrm{Wnt} / \beta$-catenin signaling and MRP1 and LRP downregulation. Additionally, inhibition of CK2 activity decreased p-DVL-2 ${ }^{\text {Ser143 }}$ levels, implying DVL-2 phosphorylation at Ser143 by CK2 promoted activation of Wnt/ $\beta$-catenin signaling. Analysis of cleaved-caspase-3 levels in the four groups revealed that CX4945 treatment increased cisplatin-induced apoptosis in A549/DDP cells by downregulating MRP1 and LRP, with this finding confirmed by flow cytometric analysis. Furthermore, the $\mathrm{IC}_{50}$ value of CX4945 pre-treated cells was lower compared with that of parental A549/DDP cells. These results indicated that CX4945 reversed cisplatin resistance by blocking Wnt/ $\beta$-catenin signaling and downregulating MRP1 and LRP levels.

In conclusion, the results from the present study suggest that $\mathrm{Wnt} / \beta$-catenin signaling can be clinically targeted using CK2 inhibitors to induce sensitivity to platinum-based chemotherapeutics used for treating lung cancer. These results support the combined application of cisplatin with CX4945 for the treatment of NSCLC. Further studies are required to confirm that CX4945 will also function in vivo in order to predict the clinical benefit for patients. Additionally, the use of only one DDP resistant cell line may be a potential limitation of the present study. Future studies will address this and also investigate the involvement of associated signaling pathways, besides the Wnt signaling pathway.

\section{Acknowledgements}

Not applicable.

\section{Funding}

This study was supported by the Scientific Research Foundation Projects of the Affiliated Hospital of Jiangsu University (grant no. 2015-013) and funds from the Zhenjiang Science and Technology Development Project (grant no. SH2013033).

\section{Availability of data and materials}

All data generated or analysed during the present study are included in this published article.

\section{Authors' contributions}

CJ and PS conceived the study and designed the experiments. CJ performed the experiments. CJ and JP collected and analysed the experimental results. $\mathrm{CJ}$ drafted and revised the article.

\section{Ethics approval and consent to participate}

Not applicable.

\section{Patient consent for publication}

Not applicable. 


\section{Competing interests}

The authors declare that they have no competing interests.

\section{References}

1. Torre LA, Siegel RL and Jemal A: Lung cancer statistics. Adv Exp Med Biol 893: 1-19, 2016.

2. Maconachie R, Mercer T, Navani N and McVeigh G; Guideline Committee: Lung cancer: Diagnosis and management: Summary of updated NICE guidance. BMJ 364: 11049, 2019.

3. Hellmann MD, Li BT, Chaft JE and Kris MG: Chemotherapy remains an essential element of personalized care for persons with lung cancers. Ann Oncol 27: 1829-1835, 2016.

4. Lunacsek OE, Ravelo A, Coutinho AD, Hazard SJ, Green MR, Willey J, Eaddy M and Goertz HP: First-line treatment with bevacizumab and platinum doublet combination in Non-squamous non-small cell lung cancer: A retrospective cohort study in US oncology community practices. Drugs Real World Outcomes 3: 333-343, 2016.

5. Willers H, Azzoli CG, Santivasi WL and Xia F: Basic mechanisms of therapeutic resistance to radiation and chemotherapy in lung cancer. Cancer J 19: 200-207, 2013.

6. Mirzaei SA, Reiisi S, Ghiasi TP, Shekari A, Aliakbari F, Azadfallah E and Elahian F: Broad blocking of MDR efflux pumps by acetylshikonin and acetoxyisovalerylshikonin to generate hypersensitive phenotype of malignant carcinoma cells. Sci Rep 8: 3446, 2018.

7. Wang Y, Zhang L, Yang J, Li B and Wang J: CDH13 promoter methylation regulates cisplatin resistance of non-small cell lung cancer cells. Oncol Lett 16: 5715-5722, 2018.

8. Rose MC, Kostyanovskaya E and Huang RS: Pharmacogenomics of cisplatin sensitivity in non-small cell lung cancer. Genomics Proteomics Bioinformatics 12: 198-209, 2014.

9. Zhou BG, Wei CS, Zhang S, Zhang Z and Gao HM: Matrine reversed multidrug resistance of breast cancer MCF-7/ADR cells through PI3K/AKT signaling pathway. J Cell Biochem 119: 3885-3891, 2018

10. Pang L, Lu J, Huang J, Xu C, Li H, Yuan G, Cheng X and Chen J: Upregulation of miR-146a increases cisplatin sensitivity of the non-small cell lung cancer A549 cell line by targeting JNK-2. Oncol Lett 14: 7745-7752, 2017.

11. Cui J, Jiang W, Wang S, Wang L and Xie K: Role of Wnt/ $\beta$-catenin signaling in drug resistance of pancreatic cancer. Curr Pharm Des 18: 2464-2471, 2012

12. Xu N, Shen C, Luo Y, Xia L, Xue F, Xia Q and Zhang J: Upregulated miR-130a increases drug resistance by regulating RUNX3 and Wnt signaling in cisplatin-treated HCC cell. Biochem Biophys Res Commun 425: 468-472, 2012.

13. Gao Y, Liu Z, Zhang X, He J, Pan Y, Hao F, Xie L, Li Q, Qiu X and Wang E: Inhibition of cytoplasmic GSK-3b increases cisplatin resistance through activation of $\mathrm{Wnt} / \beta$-catenin signaling in A549/DDP cells. Cancer Lett 336: 231-239, 2013.

14. Xia Y, He Z, Liu B, Wang P and Chen Y: Downregulation of $\mathrm{Meg} 3$ enhances cisplatin resistance of lung cancer cells through activation of the WNT/ $\beta$-catenin signaling pathway. Mol Med Rep 12: 4530-4537, 2015.

15. Zhang Q, Zhang B, Sun L, Yan Q, Zhang Y, Zhang Z, Su Y and Wang C: MicroRNA-130b targets PTEN to induce resistance to cisplatin in lung cancer cells by activating Wnt $/ \beta$-catenin pathway. Cell Biochem Funct 36: 194-202, 2018.

16. Hanif IM, Hanif IM, Shazib MA, Ahmad KA and Pervaiz S: Casein Kinase II: An attractive target for anti-cancer drug design. Int J Biochem Cell Biol 42: 1602-1605, 2010.

17. Litchfield DW: Protein kinase CK2: Structure, regulation and role in cellular decisions of life and death. Biochem J 369: 1-15, 2003.

18. Zou J, Luo H, Zeng Q, Dong Z, Wu D and Liu L: Protein kinase CK2 $\alpha$ is overexpressed in colorectal cancer and modulates cell proliferation and invasion via regulating EMT-related genes. J Transl Med 9: 97, 2011

19. Benavent AF, Capobianco CS, Garona J, Cirigliano SM, Perera Y, Urtreger AJ, Perea SE, Alonso DF and Farina HG: CIGB-300, an anti-CK 2 peptide, inhibits angiogenesis, tumor cell invasion and metastasis in lung cancer models. Lung Cancer 107: 14-21, 2017.

20. Liu Y, Amin EB, Mayo MW, Chudgar NP, Bucciarelli PR, Kadota K, Adusumilli PS and Jones DR: CK $2 \alpha^{\prime}$ drives lung cancer metastasis by targeting BRMS1 nuclear export and degradation. Cancer Res 76: 2675-2686, 2016.
21. Shimada K, Anai S, Marco DA, Fujimoto K and Konishi N: Cyclooxygenase 2-dependent and independent activation of Akt through casein kinase $2 \alpha$ contributes to human bladder cancer cell survival. BMC Urol 11: 8, 2011.

22. Zhang S, Yang YL, Wang Y, You B, Dai Y, Chan G, Hsieh D, Kim IJ, Fang LT, Au A, et al: CK2 $\alpha$, over-expressed in human malignant pleural mesothelioma, regulates the Hedgehog signaling pathway in mesothelioma cells. J Exp Clin Cancer Res 33: 93, 2014.

23. Zhang HX, Jiang SS, Zhang XF, Zhou ZQ, Pan QZ, Chen CL, Zhao JJ, Tang Y, Xia JC and Weng DS: Protein kinase CK2 $\alpha$ catalytic subunit is overexpressed and serves as an unfavorable prognostic marker in primary hepatocellular carcinoma. Oncotarget 6: 34800-34817, 2015.

24. Bae JS, Park SH, Kim KM, Kwon KS, Kim CY, Lee HK, Park BH, Park HS, Lee H, Moon WS, et al: CK2 $\alpha$ phosphorylates $\mathrm{DBC} 1$ and is involved in the progression of gastric carcinoma and predicts poor survival of gastric carcinoma patients. Int J Cancer 136: 797-809, 2015.

25. Dowling JE, Alimzhanov M, Bao L, Chuaqui C, Denz CR, Jenkins E, Larsen NA, Lyne PD, Pontz T, Ye Q, et al: Potent and selective CK2 kinase inhibitors with effects on Wnt pathway signaling in vivo. ACS Med Chem Lett 7: 300-305, 2016.

26. Seldin DC, Landesman-Bollag E, Farago M, Currier N, Lou D and Dominguez I: CK2 as a positive regulator of Wnt signalling and tumourigenesis. Mol Cell Biochem 274: 63-67, 2005.

27. Lee YN, Gao Y and Wang HY: Differential mediation of the Wnt canonical pathway by mammalian Dishevelleds-1, -2 and -3 . Cell Signal 20: 443-452, 2008.

28. Luo K, Gu X, Liu J, Zeng G, Peng L, Huang H, Jiang M, Yang P, Li M, Yang Y, et al: Inhibition of disheveled-2 resensitizes cisplatin-resistant lung cancer cells through down-regulating Wnt/ $\beta$-catenin signaling. Exp Cell Res 347: 105-113, 2016.

29. Song DH, Sussman DJ and Seldin DC: Endogenous protein kinase CK2 participates in Wnt signaling in mammary epithelial cells. J Biol Chem 275: 23790-23797, 2000.

30. Livak KJ and Schmittgen TD: Analysis of relative gene expression data using real-time quantitative PCR and the 2(-Delta Delta C(T)) method. Methods 25: 402-408, 2001.

31. Clevers $\mathrm{H}$ and Nusse $\mathrm{R}$ : Wnt $/ \beta$-catenin signaling and disease. Cell 149: 1192-1205, 2012.

32. Smalley MJ, Signoret N, Robertson D, Tilley A, Hann A, Ewan K, Ding Y, Paterson H and Dale TC: Dishevelled (Dvl-2) activates canonical Wnt signalling in the absence of cytoplasmic puncta. J Cell Sci 118: 5279-5289, 2005.

33. Lee KH, Johmura Y, Yu LR, Park JE, Gao Y, Bang JK, Zhou M, Veenstra TD, Yeon Kim B and Lee KS: Identification of a novel Wnt5a-CK1ع-Dvl2-Plk1-mediated primary cilia disassembly pathway. EMBO J 31: 3104-3117, 2012

34. Cadigan KM and Waterman ML: TCF/LEFs and Wnt signaling in the nucleus. Cold Spring Harb Perspect Biol 4: pii: a007906, 2012.

35. Angers $\mathrm{S}$ and Moon RT: Proximal events in Wnt signal transduction. Nat Rev Mol Cell Biol 10: 468-477, 2009.

36. Liu C, Gong Q, Chen T, Lv J, Feng Z, Liu P and Deng Z: Treatment with 20(S)-ginsenoside $\mathrm{Rg} 3$ reverses multidrug resistance in A549/DDP xenograft tumors. Oncol Lett 15: 4376-4382, 2018.

37. Wu Q, Yang Z, Nie Y, Shi Y and Fan D: Multi-drug resistance in cancer chemotherapeutics: Mechanisms and lab approaches. Cancer Lett 347: 159-166, 2014.

38. Gottesman MM: Mechanisms of cancer drug resistance. Annu Rev Med 53: 615-627, 2002.

39. Ku MJ, Park JW, Ryu BJ, Son YJ, Kim SH and Lee SY: CK2 inhibitor CX4945 induces sequential inactivation of proteins in the signaling pathways related with cell migration and suppresses metastasis of A549 human lung cancer cells. Bioorg Med Chem Lett 23: 5609-5613, 2013.

40. Wei H, Lu W, Li M, Zhang Q and Lu S: Concomitance of P-gp/LRP expression with EGFR mutations in exons 19 and 21 in non-small cell lung cancers. Yonsei Med J 57: 50-57, 2016.

41. Backos DS, Franklin CC and Reigan P: The role of glutathione in brain tumor drug resistance. Biochem Pharmacol 83: 1005-1012, 2012.

42. Huang H, Liu J, Meng Q and Niu G: Multidrug resistance protein and topoisomerase 2 alpha expression in non-small cell lung cancer are related with brain metastasis postoperatively. Int J Clin Exp Pathol 8: 11537-11542, 2015. 
43. Javid J, Mir R, Mirza M, Imtiyaz A, Prasant Y, Mariyam Z, Julka PK, Mohan A, Lone M, Ray PC and Saxena A: CC genotype of anti-apoptotic gene BCL-2 (-938 C/A) is an independent prognostic marker of unfavorable clinical outcome in patients with non-small-cell lung cancer. Clin Transl Oncol 17: 289-295, 2015.

44. Kelland L: The resurgence of platinum-based cancer chemotherapy. Nat Rev Cancer 7: 573-584, 2007.

45. Macdonald BT, Tamai K and He X: Wnt/beta-catenin signaling: Components, mechanisms, and diseases. Dev Cell 17: 9-26, 2009.

46. Nusse $R$ and Clevers $H$ : Wnt/ $\beta$-catenin signaling, disease and emerging therapeutic modalities. Cell 169: 985-999, 2017.
47. Kim J and Kim SH: Druggability of the CK2 inhibitor CX-4945 as an anticancer drug and beyond. Arch Pharm Res 35: 1293-1296, 2012.

48. Kim J and Hwan KS: CK2 inhibitor CX-4945 blocks TGF- $\beta 1$-induced epithelial-to-mesenchymal transition in A549 human lung adenocarcinoma cells. PLoS One 8: e74342, 2013.

49. So KS, Rho JK, Choi YJ, Kim SY, Choi CM, Chun YJ and Lee JC: AKT/mTOR down-regulation by CX-4945, a CK2 inhibitor, promotes apoptosis in chemorefractory non-small cell lung cancer cells. Anticancer Res 35: 1537-1542, 2015. 